\title{
CISTO ODONTOGÊNICO CALCIFICANTE - RELATO DE CASO
}

Luiz Antonio NERONE, Delson João COSTA, José Mário Domingos FRAIZ, Paulo Roberto MÜLLER, Nelson Luís Barbosa REBELLATO

O cisto odontogênico calcificante é uma lesão incomum com comportamento clínico e histopatológico variável. Em alguns casos parecem ser cistos não-neoplásicos, enquanto em outros casos não apresentam características císticas, sendo considerados como neoplasias. A forma cística é a mais freqüente e a característica histológica mais comum é a presença de um número variável de células fantasmas no componente epitelial. A região de caninos e incisivos é a de maior incidência da lesão e a média de idade dos pacientes é de 33 anos. Geralmente se apresenta como uma lesão unilocular radiolúcida bem definida, podendo apresentar estruturas radiopacas no interior. O objetivo deste trabalho é apresentar o caso clínico da paciente L.G., 39 anos, gênero feminino, leucoderma, que foi encaminhada ao serviço de Cirurgia Buco-Maxilo-Facial da UFPR. A lesão apresentava-se assintomática e foi um achado durante o exame radiográfico, no qual observou-se a presença de uma lesão radiolúcida, estendendo-se da região do dente 12 ao 23. Os dentes 12, 11 e 21 apresentavam tratamento endodôntico e o dente 22 não respondeu ao teste de vitalidade. A hipótese diagnóstica foi de cisto periapical e o tratamento proposto foi a enucleação da lesão. O diagnóstico histopatológico foi de cisto odontogênico epitelial calcificante. 